\title{
Raynaud's phenomenon as side effect of beta-blockers in hypertension
}

\author{
A J MARSHALL，C J C ROBERTS， D W BARRITT
}

British Medical fournal, 1976, 1, 1498-1499

In four patients the skin temperature was measured in a temperature-controlled room using a thermistor thermometer attached to a finger after $80 \mathrm{mg}$ propranolol by mouth and $80 \mathrm{mg}$ oxprenolol by mouth on separate occasions. No treatment had been given for the previous three days and the patients rested for two hours before and

\section{Summary}

A series of 102 hypertensive patients were assessed for the frequency of symptoms of Raynaud's phenomenon and absent peripheral pulses. Out of 21 patients receiving methyldopa alone only one had cold hands and feet whereas among patients on beta-blockers the incidence was $50 \%$. The frequency of both symptoms and absent pulses was highest in patients taking propranolol compared with those taking atenolol or oxprenolol. Patients without a foot pulse were much more likely to have cold hands. A change from propranolol to oxprenolol in some symptomatic patients resulted in improvement. In two patients the skin temperature fell after an $80-\mathrm{mg}$ dose of propranolol. The mechanism by which beta-blockers induce Raynaud's phenomenon is still not clear.

\section{Introduction}

Hypertension is usually asymptomatic, and treatment undoubtedly improves prognosis. ${ }^{1}$ The ideal hypotensive agent should not itself induce symptoms, as side effects to treatment are a known cause of drug defaulting." Beta-adrenergic-blocking drugs have become established in hypertension and are often the treatment of first choice. Side effects are relatively mild. Cold hands and feet have been reported as the commonest, ${ }^{3}$ although this symptom has not been mentioned in some trials. ${ }^{45}$ The purpose of this study was to assess and compare the incidence of Raynaud's phenomenon and the absence of peripheral pulses in hypertensive patients treated with three beta-blockers-propranolol, oxprenolol, and atenolol.

\section{Patients and methods}

Altogether 102 consecutive patients attending a hypertensive clinic were studied; 81 were receiving beta-blockers and 21 methyldopa. No other antihypertensive treatment was being given. The daily dose ranges were: propranolol $80-960 \mathrm{mg}$, oxprenolol $160-1280 \mathrm{mg}$, atenolol $100-400 \mathrm{mg}$, and methyldopa $500-3000 \mathrm{mg}$.

Each patient answered a questionnaire posing three questions designed to determine the occurrence of symptoms of cold extremities. These were: (1) Do you suffer from cold hands and/or feet ?; (2) Have you noticed an accompanying change of skin colour to white or blue ?; (3) Do you notice this sympton in cold and/or warm temperatures? Patients stated whether the symptoms were present and whether they had noticed them in the years before treatment. They were designated "symptomatic" only if a colour change accompanied cold hands and feet. Two independent observers then palpated and recorded the presence or absence of the dorsalis pedis and posterior tibial pulses with the patient supine. Heart rate and blood pressure were measured after five minutes at rest. Ten patients with symptoms on propranolol were changed to oxprenolol at an equal dose and assessed again after six weeks.

Department of Medicine, Bristol Royal Infirmary, Bristol BS2 8HW A J MARSHALL, MB, MRCP, senior medical registrar

D W BARRITT, MD, FRCP, consultant physician

C J C ROBERTS, MB, MRCP, lecturer in clinical pharmacology six hours after each drug. Skin temperature and heart rate were recorded at 15-minute intervals throughout.

Statistical analyses were performed with either the $\%^{2}$ or Student's $t$ test.

\section{Results}

The incidence of symptoms of Raynaud's phenomenon and the absence of one or more peripheral pulses was significantly higher in patients treated with beta-blockers than in those on methyldopa $(P<0.025)$ (table I). Symptoms developed more frequently in the group treated with propranolol than in those treated with oxprenolol $(P<0.005)$ and there was a higher incidence of absent pulses with propranolol (propranolol $v$ oxprenolol, $\mathrm{P}<0.025$; propranolol $v$ atenolol, $P<0.05)$. There was no significant difference between oxprenolol and atenolol. No patient considered that cold hands and feet with colour change had been present before antihypertensive treatment had begun. Those with symptoms after treatment developed them in both hands and feet.

TABLE I-Incidence of cold extremities in treatment groups

\begin{tabular}{|c|c|c|c|c|}
\hline & & No of patients & $\begin{array}{l}\text { No }\left("{ }^{\prime \prime}\right) \text { with } \\
\text { Raynaud's } \\
\text { phenomenon }\end{array}$ & $\begin{array}{c}\text { No }\left({ }^{\prime}(0) \text { with one }\right. \\
\text { or more pulses } \\
\text { absent }\end{array}$ \\
\hline $\begin{array}{c}\text { Methyldopa } \\
\text { Beta-blockers } \\
\text { Propranolol } \\
\text { Oxprenolol } \\
\text { Atenolol }\end{array}$ & $\begin{array}{l}\cdots \\
\cdots \\
\cdots \\
\cdots\end{array}$ & $\begin{array}{l}34 \\
27 \\
20\end{array}$ & $\begin{array}{l}11(5)^{*} \\
33(41) \\
20(59) \\
6(22) \dagger \\
7(35)\end{array}$ & $\begin{array}{c}1 \\
26(5)^{*} \\
17(50) \\
5(19) \dagger \\
4(20) \dagger\end{array}$ \\
\hline
\end{tabular}

* Significantly less than with beta-blockers $(P<0.025)$

+ Significantly less than with propranolol $(P<0 \cdot 05)$.

Symptoms occurred in some patients with all pulses palpable, but the absence of foot pulses was always associated with Raynaud's phenomenon. There was no association between the development of symptoms and the dose of beta-blocker.

Table II compares the four treatment groups. Significant differences $(P<0.05)$ were found in the incidence of smokers, which was higher in the oxprenolol group than in the atenolol group, and in the treated diastolic blood pressure, which was higher in the oxprenolol group than in the propranolol group. Significant differences in heart rate were found between all four groups. The mean durations of treatment in the four groups were: atenolol four months, propranolol 32 months, oxprenolol 41 months, and methyldopa 62 months. Of the 10

TABLE II-Comparison of four treatment groups. Mean values are given $\pm S D$

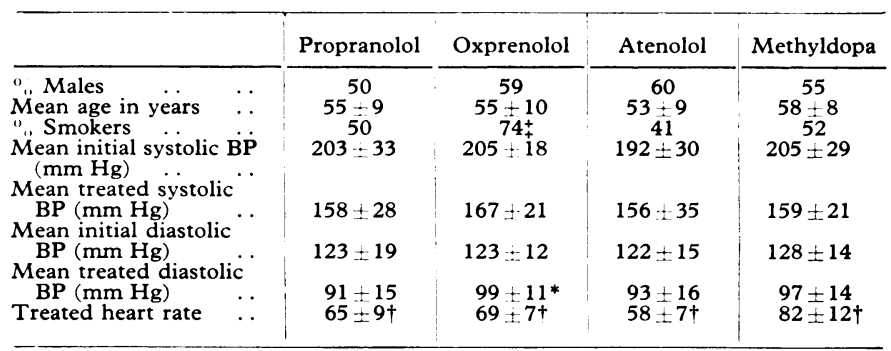

* Significantly higher $(P<0.05)$ than in propranolol group.

+ Significantly different from all other groups $(P<0.05)$
$\ddagger$ Significantly higher $(P<0.05)$ than in atenolol group. 
patients changed from propranolol to oxprenolol, six had an improvement in their symptoms, in two they remained static, and two experienced a burning sensation in the digits. Four of the six patients whose symptoms improved regained a previously impalpable foot pulse.

In two patients given a single $80-\mathrm{mg}$ dose of propranolol the skin temperature fell by 9 and $3.5 \mathrm{C}$ respectively, but after $80 \mathrm{mg}$ oxprenolol it did not change by more than $1 \mathrm{C}$ in either case. The skin temperature began to fall about 45 minutes after the time of maximum bradycardia and was accompanied by the development of peripheral cyanosis. In the other two cases no consistent change in skin temperature was recorded after either drug.

\section{Discussion}

These results confirm the significant incidence of Raynaud's phenomenon and absent peripheral pulses associated with the use of beta-adrenergic-receptor blocking agents in hypertension. Differences in the incidence of cold hands and feet with individual agents occurred, and propranolol was implicated as being particularly apt to cause this effect.

Differences between the treatment groups were not related to their clinical characteristics. Though a degree of atheromatous vascular disease is likely to be present in hypertension, it would occur in major leg arteries and would not explain the development of cold hands after beta-blockade. The severity of the hypertension and its subsequent control were similar in both the methyldopa and beta-blockade groups. Smoking could be an additional factor, both by predisposing to atherosclerosis and by the vasoconstrictive effect of nicotine. Nevertheless, we found no association between the habit and this syndrome. The differences in durations of treatment between the groups did not match the differences in incidence of Raynaud's phenomenon, which, together with the fall in skin temperature with colour change after a single dose of propranolol, suggests that duration of treatment is not a major factor. The higher incidence of Raynaud's phenomenon in the patients taking beta-blockers compared with that in the patients on methyldopa suggests that heta-blockade is the cause.

The mechanism is still not clear. Beta-blockade reduces cardiac output, and arteriolar constriction in voluntary muscle results in decreased total limb blood flow. Possibly redistribution of blood towards surface structures together with a slow peripheral perfusion causes excessive cooling of blood. A vasoconstrictive reflex would then be stimulated to maintain the body temperature. Skin arterioles and peripheral arteries might thus constrict as a result of reflex sympathetic stimulation of alpha-receptors. Skin capillaries constrict in response to arteriolar constriction. This hypothesis is supported by the observation that skin temperature fell after beta-blockade had been established. A further contributory factor may be the increased sensitivity to alpha-receptor stimulation in peripheral blood vessels that occurs when beta-receptors are blocked. ${ }^{6}$ Thus propranolol, with its profound effects on cardiac and peripheral vasculature, caused the greatest incidence of Raynaud's phenomenon. Atenolol, being cardioselective, has a less pronounced effect on the peripheral vasculature, and oxprenolol's partial agonist activity renders it less potent both on reduction of cardiac output and in the periphery. Thus the different incidences of Raynaud's phenomenon with the three betablockers could be adequately explained. Furthermore, in two therapeutic trials of practolol, which is cardioselective and has partial agonist activity, Raynaud's phenomenon apparently did not occur ${ }^{4 ;}$

In the light of our findings we recommend that beta-blockers should be avoided in patients suffering from peripheral ischaemia. When cold hands and feet are a side effect a change of beta-blocker should be considered. It is important that future prospective trials of these agents should take full account of the incidence of this adverse effect.

\section{Referen:es}

${ }^{1}$ Hamilton, M, Thompson, E N, and Wisniewski, T K M, Lancet, 1964, 1, 235.

2 Blackwell, B, Clinical Pharmacology and Therapeutics, 1972, 13, 841.

${ }^{3}$ Zacharias, F J, Postgraduate Medical fournal, 1971, 47, suppl, p 75.

4 Prichard, B N C, Boakes, A J, and Day, G, Postgraduate Medical fournal, 1971, 47, suppl, p 84.

${ }^{5}$ Chaput de Saintonge, D M, et al, British fournal of Clinical Pharmacology, 1974, 1, 375.

${ }^{6}$ White, C de B, and Udwadia, B P, British fournal of Clinical Pharmacology, $1975,2,99$. history but with antigen A29 or AW30/31 had clinical features that distinguished them from others with valvular disease-namely, (a) isolated mitral valve disease and (b) the need for surgery, often at an early age, after a relatively short duration of symptoms.

\section{Introduction}

HLA antigens of the AW19 group are more prevalent in certain patients with acquired valvular heart disease-namely, those who, despite having chronic rheumatic heart disease, do not have a history of rheumatic fever. ${ }^{1}$ Antigens A29 and AW30/31 (members of the AW19 group) occur with the same prevalence in patients with acquired valvular disease who do have a rheumatic history as they do in control cases. Each of these antigens is significantly more common in patients with acquired valvular disease but no rheumatic history, however, than in the 